\title{
The Protective Function of Meaning of Life on Life Satisfaction Among Chinese Students in Australia and Hong Kong: A Cross-Cultural Comparative Study
}

\author{
Jia-Yan Pan, PhD; Daniel Fu Keung Wong, PhD; Lynette Joubert, PhD; \\ Cecilia Lai Wan Chan, PhD
}

\begin{abstract}
Objective: The authors compared the predictive effects of acculturative stressors and meaning of life on life satisfaction between Chinese students in Australia and in Hong Kong. Participants: In 2006, the researchers recruited 606 Chinese students studying abroad at the University of Melbourne in Australia and at 6 universities in Hong Kong. Methods: Participants completed a questionnaire that included measures of acculturative stressors, meaning of life, life satisfaction, and demographic information. Results: The Australian sample experienced a significantly higher level of acculturative stressors than did the Hong Kong sample, but life satisfaction did not differ significantly between the 2 samples. Meaning of life had a strong positive contribution and acculturative stressors had a negative contribution in predicting life satisfaction in both samples. Meaning of life partially mediated the relationship between acculturative stressors and life satisfaction in both samples. Conclusions: The authors discuss the theoretical and practical implications for Chinese students studying abroad.
\end{abstract}

Keywords: acculturation, college health, international students, life satisfaction, meaning of life

tudy-abroad students are considered a population at high risk for psychopathology or poor mental health. ${ }^{1,2}$ This is thought to result from the various acculturative stressors that they experience in their host societies. ${ }^{3}$ Acculturative stressors are the conflicts and difficulties that arise from cross-cultural contact. ${ }^{4}$ For Chinese students studying abroad, these acculturative stressors can be classified into 5 major domains. The first is languagerelated issues, such as the difficulty of listening to and

Drs Pan and Chan are with the Department of Social Work and Social Administration at the University of Hong Kong in Hong Kong, China. Drs Wong and Joubert are with the School of Nursing and Social Work at the University of Melbourne in Victoria, Australia.

Copyright $\odot 2008$ Heldref Publications speaking English ${ }^{5}$; the difficulty in understanding slang, jokes, idioms, common vocabulary, and topics of conversation $^{6}$; and a lack of confidence in using English in daily life. ${ }^{7}$ The second is academic issues, such as difficulties with course work, research, and teaching assistance ${ }^{8}$; becoming involved in class discussions ${ }^{9}$; making oral presentations and taking exams ${ }^{10}$; becoming accustomed to different classroom communication styles and types of interaction from those of the origin country ${ }^{11}$; and adjusting to changes in curriculum in the multicultural classroom. ${ }^{12}$ The third domain comprises psychosociocultural issues, such as the lack of social support networks, ${ }^{13}$ the low frequency of social interaction with domestic students, ${ }^{12}$ difficulties in intercultural communication, ${ }^{14}$ racial discrimination, ${ }^{15}$ and homesickness. ${ }^{16}$ The fourth is the financial issues, such as competition for financial assistantship ${ }^{8}$ and sharing financial aid with a spouse or children. ${ }^{17}$ The fifth includes other issues, such as political concerns ${ }^{18}$; a lack of information on services and facilities ${ }^{10}$; and concerns about food, health, housing, transportation, security, religion, and taxes. ${ }^{17}$

Berry's ${ }^{19}$ model of acculturative stress illustrates the way in which such stressors may result in varying levels of acculturative stress and diverse positive and negative psychological adaptation outcomes, which depend on various moderating factors. In the past few decades, however, researchers of migration and mental health have intensively focused on negative health outcomes. Hovey and King ${ }^{20}$ extended Berry's model to demonstrate that a high level of acculturative stress can result in significantly high levels of depressive symptoms and suicide ideation among immigrant populations. Studies of international students have also shown that various domains of acculturative stressors significantly affect students' psychological adjustment. For example, low English-language proficiency is a significant predictor of depressive symptoms among Chinese students 
attending school in Australia ${ }^{21}$ and a major determinant of sociocultural adjustment, as indexed by intercultural-social self-efficacy. ${ }^{22}$ Contact with host nationals is also related to academic, social, and psychological adjustment outcomes for international students. ${ }^{1,10,23}$ In addition, researchers have also found that perceived racial discrimination exerts a negative influence on the psychological and social adaptation of migrants. . $^{1,15,24}$

Resilience research in the past 3 decades has demonstrated that a subgroup of a high-risk population can experience positive health outcomes despite adverse life circumstances. ${ }^{25}$ Acculturation experiences sometimes enhance mental health. ${ }^{26}$ Recent studies have found that the majority of Chinese students have settled successfully in Australia, in spite of the difficulties and emotional troubles that accompany acculturation. ${ }^{27}$ Other research has shown that the majority of study-abroad students in Australia and New Zealand have experienced positive affect and life satisfaction. ${ }^{10,28}$ Similar findings have also been reported for Chinese American college students. ${ }^{29}$

Many factors contribute to the life satisfaction of international students in a host society. Ward and Masgoret ${ }^{10}$ cite such factors as greater language proficiency, more cultural inclusiveness, more contact with host nationals, a positive attitude in the host community toward international students, more available social support, and less discrimination. Laubscher $^{30}$ also found that low levels of acculturative stress were associated with a higher level of general satisfaction with the travel experience. Similarly, Neto ${ }^{31}$ found that social adaptation difficulties were negatively correlated with life satisfaction among Portuguese immigrants in France.

Resilience researchers have identified numerous protective factors - such as meaning of life $^{25}$ - that mitigate the negative effects of risk factors and promote positive adaptation outcomes. ${ }^{32}$ Meaning of life is "the cognizance of order, coherence, and purpose in one's existence, the pursuit and attainment of worthwhile goals, and an accompanying sense of fulfillment." 33 (p221) Meaning comes from various sources in the lives of individuals ${ }^{34}$; Wong ${ }^{35}$ developed the Personal Meaning Profile (PMP) to measure the sources of a meaningful life, which include achievement, religion, relationships, self-transcendence (ie, focus on the value of serving others), self-acceptance, intimacy, and fair treatment. An individual's concept of meaning of life includes both culturally specific and universal elements. ${ }^{36}$ Researchers in one cross-cultural comparative study ${ }^{37}$ showed that the most important sources of meaning of life for Australians were participation in personal relationships and leisure activities, personal growth, and meeting basic needs, which is consistent with findings among Canadians. ${ }^{38}$ In contrast, investigators of Asian populations have identified certain cultural factors that are related to meaning of life. Lin $^{39}$ found that in addition to the 7 factors included in Wong's PMP, Chinese people also seek personal meaning from family, self-development, and being close to nature and authenticity (ie, to understand nature, follow it, and flow with it). Meaning of life in Chinese culture appears to be framed in relation to others, society, and nature.
The link between meaning of life and positive psychological well-being is generally established. ${ }^{40}$ Several researchers have found that the attainment of meaning in life is significantly associated with life satisfaction. ${ }^{39,41-43}$ Furthermore, meaning of life is more strongly associated with the positive dimensions of well-being (life satisfaction and positive affect) than with negative dimensions (psychological distress and negative affect). ${ }^{42}$ Zika and Chamberlain $^{41}$ examined 3 personal variables (locus of control, assertiveness, and meaning in life) in relation to psychological well-being and found that meaning in life was the most consistent predictor of positive well-being among college students. Wallace and Lahti $^{44}$ further found that meaning of life partially mediated the link between perceived stress and life satisfaction in a sample of older adults. Although investigators have found evidence that supports a relationship between meaning of life and positive psychological well-being, few have investigated this relationship in the context of acculturation for migrant populations. Because the application of the resilience framework in acculturation research is still in its infancy, researchers must begin to identify the protective factors that promote positive adaptation in the context of acculturation. By identifying and investigating the more positive contributions to mental health, we can examine preventive strategies that may improve the mental health of migrant student populations. ${ }^{45}$ Moreover, the acculturation process for migrants in different countries appears to be contextualized rather than homogeneous. Thus, further comparative studies are needed to understand the various acculturation phenomena across host societies. $^{27}$

In this study, we examined and compared the predictors of life satisfaction between Chinese international students attending a university in Australia and students from mainland China in Hong Kong universities. We also compared and attempted to identify the protective mechanism of meaning of life in relation to acculturative stressors and life satisfaction between the 2 groups. We generated 3 hypotheses.

1. Chinese students in Australia will experience a higher level of acculturative stressors and a lower level of global life satisfaction than will mainland students in Hong Kong.

2. Meaning of life will positively predict life satisfaction, whereas acculturative stressors will negatively predict life satisfaction among Chinese students attending school in Australia and Hong Kong.

3. Meaning of life will mediate the relationship between acculturative stress and life satisfaction.

\section{METHODS \\ Procedure}

We obtained ethical approval from the human research ethics committees of the University of Hong Kong and 
the University of Melbourne. We sent students an invitation letter with a Web address linking to an online questionnaire designed for the study to elaborate the study's purpose and explain its confidential and voluntary nature. In Hong Kong, we distributed an electronic invitation letter via university Web mail to mainland Chinese graduate students who were studying at 6 Hong Kong universities. In Australia, we sent the invitation letter by e-mail, with the help of the international student office, to international students at the University of Melbourne who came from mainland China, Hong Kong, Taiwan, and Macau. We mailed hard copies of the questionnaire to student residential halls in Hong Kong and posted hard copies on notice boards across the University of Melbourne campus. The questionnaire was in Chinese. Participants wrote their university e-mail address on a separate sheet of the questionnaire to avoid duplicate responses. We sent a souvenir to each student who completed the questionnaire.

\section{Participants}

A total of 606 participants completed the questionnaire. Four hundred participants were Chinese students studying in 6 Hong Kong universities, and 206 were mainland Chinese students studying at the University of Melbourne (see Table 1).

\section{Measures}

\section{Acculturative Stressor Scale for Chinese Students}

We developed the Acculturative Stressor Scale for Chinese Students (ASSCS) to measure the acculturative stressors that Chinese students experience in their daily lives in their host country or region. We interviewed 14 mainland Chinese graduate students regarding the adjustment problems they encountered in Hong Kong. We generated 100 items from the in-depth interviews and after expert and wording checks, retained 84 , which we then pilot-tested for item analysis in a sample of 189 mainland Chinese students in 4 universities in Hong Kong. We selected the items according to the criteria in the following sequence: (1) less than $60 \%$ of the participants reported experiencing the item as either "not at all" or "not applicable"; (2) the inter-item correlation was less than .80; (3) the corrected item-total correlation was greater than .40; and (4) the pattern coefficient in exploratory factor analysis was greater than .50 . Last, we retained 18 items to form the final version of the ASSCS, which we validated in a sample of 400 mainland Chinese students in 6 universities in Hong Kong. The exploratory factor analysis that we conducted in this sample suggested 4 factors: language deficiency, cultural difference, academic work, and social interaction. In the Australian sample, we added 9 items to represent the other 2 acculturative stressors that Chinese students commonly experience

\begin{tabular}{|c|c|c|c|c|}
\hline \multirow[b]{2}{*}{ Characteristic } & \multicolumn{2}{|c|}{ Hong Kong sample } & \multicolumn{2}{|c|}{ Australian sample } \\
\hline & $n$ & $\%$ & $n$ & $\%$ \\
\hline \multicolumn{5}{|l|}{ Sex } \\
\hline Male & 200 & 50 & 68 & 33 \\
\hline Female & 200 & 50 & 138 & 67 \\
\hline \multicolumn{5}{|c|}{$\begin{array}{l}\text { Duration of residence } \\
\text { in host society (y) }\end{array}$} \\
\hline$\leq 0.5$ & 155 & 38.8 & 38 & 18.4 \\
\hline $0.5-1$ & 27 & 6.8 & 25 & 12.1 \\
\hline $1-2$ & 79 & 19.8 & 39 & 18.9 \\
\hline $2-3$ & 72 & 18.0 & 37 & 18.0 \\
\hline$>3$ & 67 & 16.8 & 67 & 32.6 \\
\hline \multicolumn{5}{|c|}{ Level of education } \\
\hline $\mathrm{PhD}$ & 256 & 64.0 & 95 & 46.1 \\
\hline Master's & 144 & 36.0 & 97 & 47.1 \\
\hline Other & 0 & 0 & 14 & 6.8 \\
\hline \multicolumn{5}{|l|}{ Age $(y)$} \\
\hline$\leq 23$ & 72 & 18.0 & 128 & 62.1 \\
\hline $24-30$ & 269 & 76.3 & 74 & 35.9 \\
\hline$>30$ & 59 & 14.8 & 4 & 1.9 \\
\hline \multicolumn{5}{|l|}{ Marital status } \\
\hline Single & 299 & 74.8 & 190 & 92.2 \\
\hline Married & 97 & 24.3 & 12 & 5.8 \\
\hline Other & 4 & 1.0 & 4 & 1.9 \\
\hline \multicolumn{5}{|c|}{ Religiously active } \\
\hline No & 357 & 89.3 & 152 & 73.8 \\
\hline Yes & 43 & 10.8 & 54 & 26.2 \\
\hline Total & 400 & 100 & 206 & 100 \\
\hline
\end{tabular}


in Western countries: discrimination and financial problems. We adopted these 9 items from the Acculturative Stress Scale for International Students, ${ }^{46}$ the Index of Life Stress for Asian Students, ${ }^{47}$ and the Juarez International Student Stress Test. ${ }^{48}$ The discrimination factor comprises 4 items, one of which is "many opportunities are denied to me because I am not a local student or resident." The factor of financial problems comprises 5 items, including "my financial situation makes my life here very hard." Participants indicate the degree to which they have experienced or are experiencing the adjustment problems listed on the scale. The responses, rated on a 4-point Likert scale, were 0 (not at all), 1 (a little), 2 (moderate), and 3 (a $l o t$ ). A higher score indicates a greater level of the acculturative stressor. The validation of the ASSCS in the sample illustrated its sound psychometric properties: the Cronbach alpha coefficient and Guttman split-half reliability were .89 and .85 in the Hong Kong sample and .91 and .90 in the Australian sample. The Cronbach alpha coefficient of the subscales ranged from .74 to .84 in the Hong Kong sample and from .64 to .81 in the Australian sample. The Guttman split-half reliability of the subscales ranged from .66 to .81 in the Hong Kong sample and from .53 to .78 in the Australian sample. The average interitem correlation of the ASSCS was .31 and .27 in the Hong Kong and Australian samples, respectively. The overall ASSCS score had a statistically significant positive correlation with negative affect in the Hong Kong sample $(r[400]=.44, p<.001)$ and in the Australian sample $(r[202]=.32, p<.001)$, and had significant negative correlations with positive affect $(r[400]=-.31$, $p<.001 ; r[202]=-.17, p<.05)$ and life satisfaction $(r[400]=$ $-.28, p<.001 ; r[202]=-.32, p<.05)$ in both samples.

\section{Chinese Personal Meaning Profile}

We adapted the Chinese Personal Meaning Profile ${ }^{39}$ (CPMP) from the $\mathrm{PMP}^{36}$ to assess the sources of life meaning among Chinese student populations. The original CPMP consisted of 87 items and 12 subscales. We excluded items with a factor loading of less than .45 in Lin's 2001 study, ${ }^{39}$ thus yielding a 55-item CPMP with 10 factors that included Self-development, Achievement, Acceptance and contentment, Western religion (participation and adoption of), Relationships (having healthy relationships with others), Pursuit of purpose, Family, Being close to nature and being authentic, Fair treatment, and Intimate relationships. Participants indicate the degree to which the items describe sources of a meaningful life. Respondents rank their responses on a 7-point Likert scale ranging from 1(not at all) to 7 (a great deal). A high score indicates a high level of meaning. The Cronbach alpha coefficient for the 55-item CPMP was .96, and the Guttman split-half reliability was .92. The CPMP score has a statistically significant positive correlation with the Purpose in Life Scale (PLS) ${ }^{49}$ and the Satisfaction with Life Scale (SWLS). ${ }^{39}$

\section{Satisfaction with Life Scale}

This scale ${ }^{50}$ measures global life satisfaction. It consists of 5 items that respondents rate on a 7-point Likert scale ranging from 1 (totally disagree) to 7 (totally agree). The total score ranges from 5 to 35 . A high score indicates a high level of global life satisfaction. Researchers ${ }^{51}$ have validated the scale among Chinese student populations. The Cronbach alpha coefficient in this study was .87, and the Guttman split-half reliability was .85 . The average interitem correlation was .58 .

\section{RESULTS}

\section{Differences in Life Satisfaction and Acculturative Stressors}

We conducted a multivariate analysis of covariance (MANCOVA) to compare the group (Australia vs Hong Kong) differences in life satisfaction and acculturative stressors. Life satisfaction and acculturative stressors were the dependent variables, and group status with 2 levels (Hong Kong vs Australia) was the independent variable in the analysis. We controlled as covariates sex, duration of stay in the host society, level of education, age, marital status, and religiosity. The results of the MANCOVA were significant $(F[5,594]=7.03, p<.001)$. The univariate $F$ test revealed that the 2 groups differed significantly in both the acculturative stressor total score and the scores on the 4 distinct domains of acculturative stressors (see Table 2). We

TABLE 2. Group Differences in Life Satisfaction and Acculturative Stressors Between the Hong Kong (HK) and Australian (A) Samples

\begin{tabular}{|c|c|c|c|c|c|c|}
\hline \multirow[b]{2}{*}{ Variable } & \multicolumn{2}{|c|}{$\begin{array}{c}\text { Hong Kong } \\
\text { sample }(n=400)\end{array}$} & \multicolumn{2}{|c|}{$\begin{array}{c}\text { Australian } \\
\text { sample }(n=206)\end{array}$} & \multirow[b]{2}{*}{$F(1,619)$} & \multirow{2}{*}{$\begin{array}{c}\text { Pairwise } \\
\text { comparison }\end{array}$} \\
\hline & $M$ & $S D$ & $M$ & $S D$ & & \\
\hline Life satisfaction & 20.16 & 6.28 & 20.99 & 6.35 & 0.00 & NS \\
\hline Total stressors & 1.21 & 0.55 & 1.43 & 0.57 & $23.79^{* *}$ & $\mathrm{HK}<\mathrm{A}$ \\
\hline Language deficiency & 1.38 & 0.74 & 1.55 & 0.73 & $11.93^{* *}$ & $\mathrm{HK}<\mathrm{A}$ \\
\hline Social interaction & 1.56 & 0.75 & 1.79 & 0.76 & $20.39^{* *}$ & $\mathrm{HK}<\mathrm{A}$ \\
\hline Academic work & 1.15 & 0.65 & 1.35 & 0.69 & $7.72^{*}$ & $\mathrm{HK}<\mathrm{A}$ \\
\hline Cultural difference & 0.74 & 0.63 & 1.03 & 0.63 & $28.22^{* *}$ & $\mathrm{HK}<\mathrm{A}$ \\
\hline Discrimination & - & - & 1.62 & 0.71 & - & - \\
\hline Financial difficulty & - & - & 0.96 & 0.76 & - & - \\
\hline
\end{tabular}


found no significant difference in life satisfaction between the Australian and Hong Kong samples. A pairwise comparison indicated that the Australian sample experienced a higher level of total acculturative stressors and stressors in language deficiency, social interaction, academic work, and cultural difference than did the Hong Kong sample. The level of acculturative stress was the second highest for discrimination $(M=1.62, S D=0.71)$ and the lowest for financial difficulty $(M=0.96, S D=0.76)$ in the Australian sample. The effect of the covariate of $\operatorname{sex}(F[5,594]=2.97$, $p<.05)$ was significant. Women $(M=21.25, S D=6.08)$ had a significantly higher level of life satisfaction than did men $(M=19.43, S D=6.47 ; F[1,598]=9.44, p<.01)$. We found no significant effect for the other covariates.

\section{Correlations of Acculturative Stress, Meaning of Life, and Life Satisfaction}

Table 3 shows the Pearson correlations of acculturative stress, meaning of life, and life satisfaction in the Australian and Hong Kong samples, respectively. In both samples, acculturative stress was negatively correlated with meaning of life $\left(r_{\mathrm{A}}=-.25, p<.001 ; r_{\mathrm{HK}}=-.23, p<.001\right)$ and life satisfaction $\left(r_{\mathrm{A}}=-.32, p<.001 ; r_{\mathrm{HK}}=-.28, p<\right.$ .001 ), and meaning of life was positively correlated with life satisfaction $\left(r_{\mathrm{A}}=.39, p<.001 ; r_{\mathrm{HK}}=.39, p<.001\right)$. We also found that specific domains of acculturative stressors were positively correlated with one another and were highly positively correlated with the total acculturative stress score in both samples (see Table 3).

\section{Predictors of Life Satisfaction in Acculturation}

We performed separate hierarchical regression analyses for the Australian and Hong Kong samples to assess the independent predictive effects of the variables of demographic factors, acculturative stressors, and meaning of life on life satisfaction. We placed sex, duration in the host society, level of education, age, and marital and religious status in the first block. We placed 4 and 6 domains of acculturative stressors in the second block of the hierarchical regression model for the Hong Kong and Australian samples, respectively. We placed 10 factors of meaning of life in the third block. The acculturative stressors made a significant joint contribution to predicting life satisfaction (see Table 4), which accounted for an additional $8 \%$ and $12 \%$ of the total variance of life satisfaction in the Hong Kong and Australian samples, respectively. The acculturative stressors of social interaction $(\beta=-.13, p<.05)$ and academic work $(\beta=-.14, p<$ $.01)$ made unique and significant contributions to negatively predicting life satisfaction in the Hong Kong sample. The acculturative stressors of academic work $(\beta=-.24, p<$ $.05)$ and financial difficulty $(\beta=-.17, p<.01)$ made significant negative contributions to predicting life satisfaction in the Australian sample. Meaning of life had a significant effect on predicting life satisfaction, which accounted for an additional $21 \%$ and $26 \%$, respectively, of the total variance of life satisfaction in the Hong Kong and Australian samples. Demographic factors exhibited no significant predictive effect on life satisfaction in either sample. To con- clude, in both samples, acculturative stressors had a negative impact on life satisfaction, and meaning of life made a strong contribution to predicting life satisfaction.

\section{Mediating Effect of Meaning of Life in the Relationship Between Acculturative Stress and Life Satisfaction}

We conducted path analysis to examine the mediating effect of meaning of life in the relationship between acculturative stress and life satisfaction. We tested the model using the procedure suggested by Frazier et $\mathrm{al}^{52}$ for the identification of mediating effects. We tested the effect separately in the Australian and Hong Kong samples. Correlational analysis showed that the predictors (acculturative stress and meaning of life) and the outcome variable (life satisfaction) had significant correlations in both samples (see Table 3). We then developed a series of regression equations for each path in the model. Figures 1 and 2 present the results of path analysis for the Hong Kong and Australian samples, respectively. Figure 1 shows that the $\beta$-weight was $-.28(p<.001)$ when life satisfaction was regressed alone on acculturative stress. When we added meaning of life to the model, the resulting $\beta$-weight was significantly reduced to -.20 (Sobel $=-3.90, p<.001)$, which suggests that meaning of life partially mediates the relationship between acculturative stress and life satisfaction. The model explained $19 \%$ of the total variance of life satisfaction in the Hong Kong sample. We observed this partial mediating effect of meaning of life also in the relationship between acculturative stress and life satisfaction in the Australian sample (Sobel $=-3.14, p<.001$; see Figure 2).

To conclude, we found that acculturative stress contributed to life satisfaction through direct and indirect pathways. On the one hand, acculturative stress had a negative impact on life satisfaction. On the other hand, acculturative stress was negatively related to meaning of life: the greater the stress, the lower the meaning of life. Furthermore, a lower level of meaning of life was associated with a lower level of life satisfaction. Therefore, more acculturative stress led to a lower level of life satisfaction directly and indirectly. The direct effects were -.20 and -.23 , and the indirect effects were -.08 and -.09 , in the Hong Kong and Australian samples, respectively.

\section{COMMENT}

\section{Group Comparison of Acculturative Stressors and Life Satisfaction}

Chinese students in Australia experienced a higher level of acculturative stressors in language deficiency, social interaction, academic work, and cultural difference than did the mainland Chinese college students in Hong Kong. This may be attributed to cultural distance and the importance of using the host language in the acculturation process. Babiker et $\mathrm{al}^{53}$ found that Australian and American cultures clustered closest to Scottish culture; Asian culture was furthest from these 3. Thus, the cultural distance between Asia and Australia is much greater than that between mainland China and Hong Kong. Our results confirm previous findings that the greater the cultural 
Pan et al

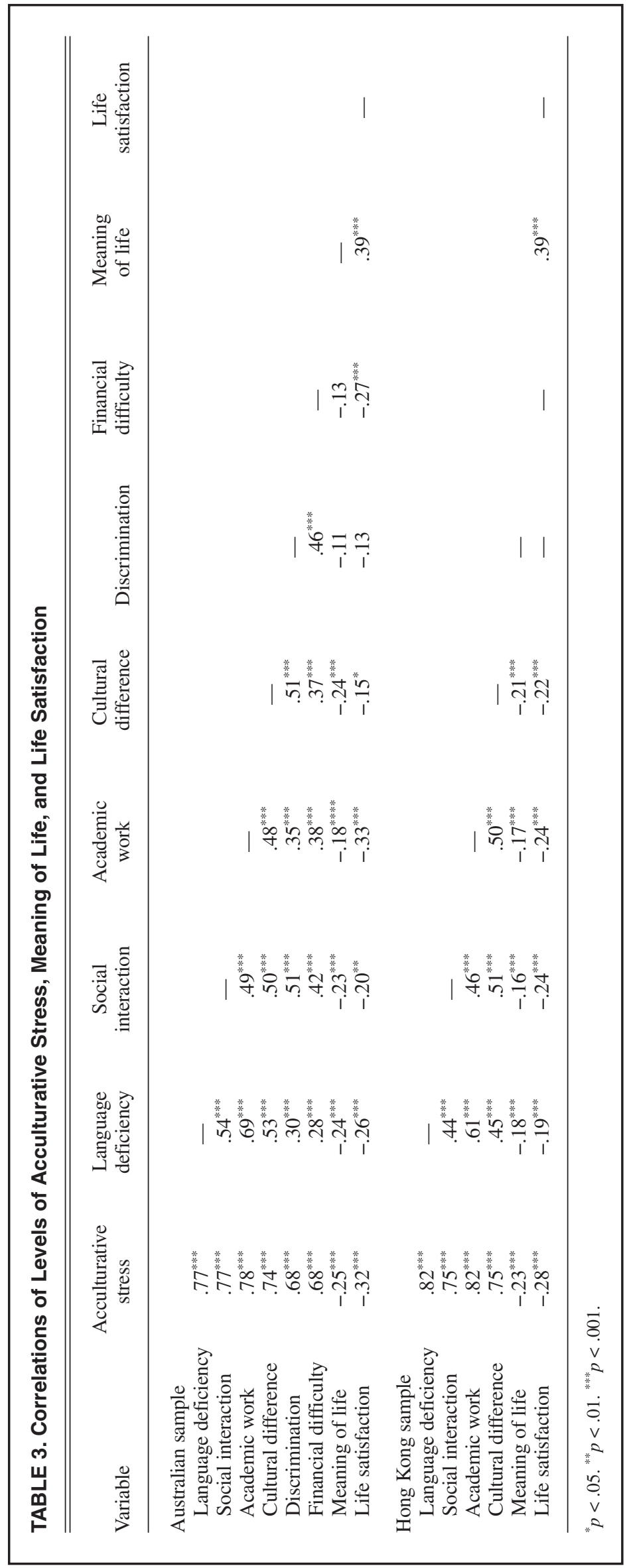


TABLE 4. Hierarchical Regression Analysis of the Effects of Demographic Factors, Acculturative Stressors, and Meaning of Life on Life Satisfaction

\begin{tabular}{|c|c|c|c|c|c|c|c|c|}
\hline \multirow[b]{2}{*}{ Predictor } & \multicolumn{4}{|c|}{ Hong Kong sample $(n=400)$} & \multicolumn{4}{|c|}{ Australian sample $(n=206)$} \\
\hline & $\beta$ & $R^{2}$ & $\Delta R^{2}$ & $\Delta F$ & $\beta$ & $R^{2}$ & $\Delta R^{2}$ & $\Delta F$ \\
\hline Step 1: Demographic factors & & .03 & - & 1.99 & & .03 & - & 1.10 \\
\hline Sex & $.13^{* *}$ & & & & .10 & & & \\
\hline Duration in host society & .02 & & & & .07 & & & \\
\hline Academic degree & .06 & & & & .02 & & & \\
\hline Age & -.08 & & & & -.02 & & & \\
\hline Marital status & .06 & & & & .12 & & & \\
\hline Actively religious & .00 & & & & -.01 & & & \\
\hline Step 2: Acculturative stressors & & .11 & .08 & $8.79^{* * * *}$ & & .16 & .12 & $4.68^{* * * *}$ \\
\hline Language deficiency & -.02 & & & & -.09 & & & \\
\hline Social interaction & $-.13^{*}$ & & & & .00 & & & \\
\hline Academic work & $-.14^{*}$ & & & & $-.24^{*}$ & & & \\
\hline Culture gap & .06 & & & & .06 & & & \\
\hline Discrimination & - & & & & .04 & & & \\
\hline Financial difficulty & - & & & & $-.17^{*}$ & & & \\
\hline Step 3: Meaning of life & & .32 & .21 & $11.91^{\text {**** }}$ & & .41 & .26 & $8.07^{* * * *}$ \\
\hline Self-development & -.10 & & & & .11 & & & \\
\hline Personal achievement & $.18^{*}$ & & & & .20 & & & \\
\hline Acceptance and contentment & $.26^{* * * *}$ & & & & $.32^{* * *}$ & & & \\
\hline Participation in Western religion & -.07 & & & & .00 & & & \\
\hline Relationship & $-.24^{* *}$ & & & & -.15 & & & \\
\hline Pursuit of purpose & -.04 & & & & -.09 & & & \\
\hline Family & $.20^{* * * *}$ & & & & .04 & & & \\
\hline Close to nature and authenticity & -.06 & & & & $-.25^{* *}$ & & & \\
\hline Fair treatment & $.25^{* * *}$ & & & & $.26^{* * *}$ & & & \\
\hline Intimate relationships & $.14^{*}$ & & & & .08 & & & \\
\hline
\end{tabular}

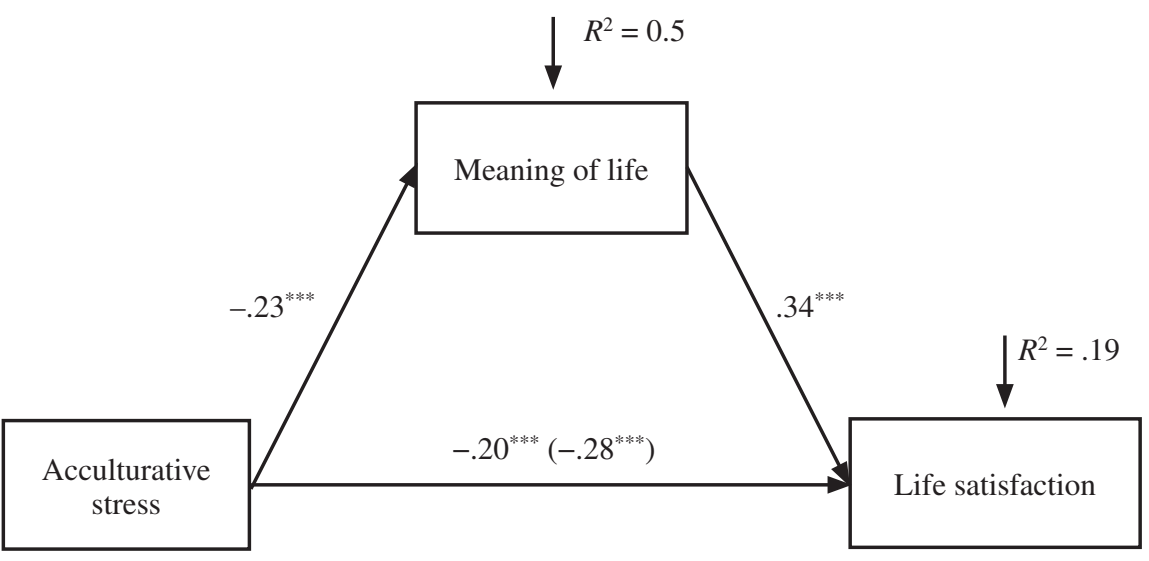

FIGURE 1. Mediating effect of the meaning of life on the relation between acculturative stress and life satisfaction in the Hong Kong sample. ${ }^{* *} p<.001$.

distance is, the more difficulties students experience in the host society ${ }^{23,54}$ and the greater the acculturative stress. ${ }^{55}$ In addition, host-language proficiency plays an important role in cross-cultural adaptation. Confidence and proficiency in the English language can facilitate the acculturation of Chinese travelers into an English-speaking country. ${ }^{2}$ English language deficiency is an impediment to making friends with the host nationals. ${ }^{10}$ We found that host-language proficiency not only influences the academic work of overseas students, but also affects their social lives and understanding of the host culture. Furthermore, the correlation coefficients were greater in the Australian sample than they were in the Hong Kong sample, which indicates that this effect was much greater in Australia than it was in Hong Kong. This is understandable, because 


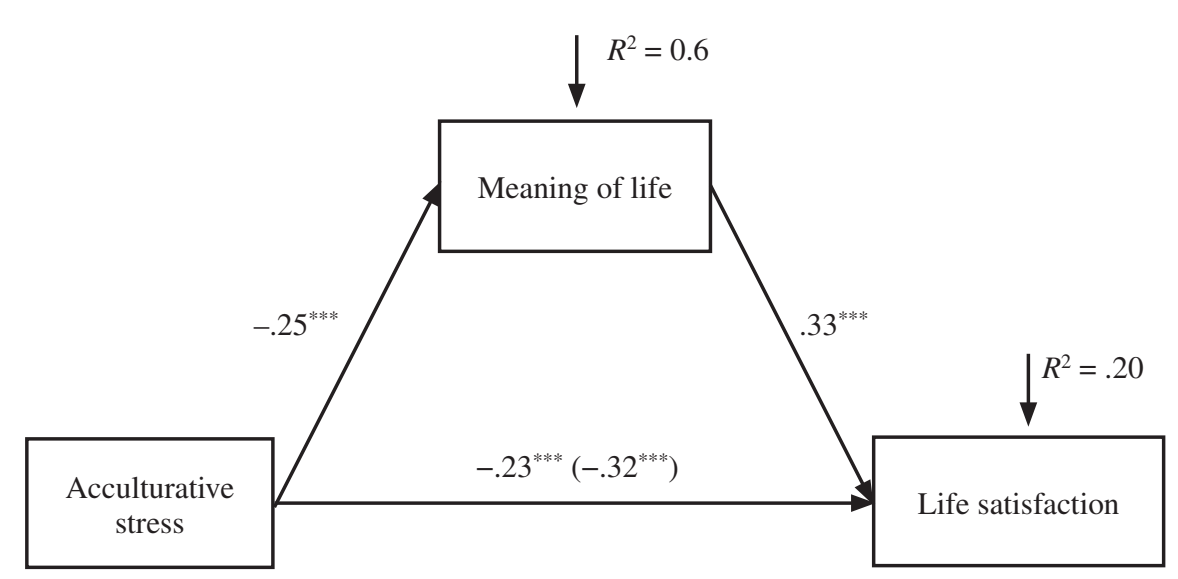

FIGURE 2. Mediating effect of the meaning of life on the relation between acculturative stress and life satisfaction in the Australian sample. ${ }^{* *} p<.001$.

English is the only language in which Chinese students can communicate with Australians, whereas mainland Chinese students in Hong Kong can communicate with residents there in either Chinese or English.

However, we observed no significant difference between the Hong Kong and Australian samples on level of life satisfaction. This is consistent with previous findings: Although Malaysian and Singaporean students in New Zealand experienced greater social difficulties than did Malaysian students in Singapore, the researchers observed no significant difference in mood disturbance between the 2 groups. ${ }^{23}$ This may be related to the similar prediction of acculturative stressors and meaning of life on life satisfaction that was found in the 2 samples in this study.

\section{Acculturative Stressors as a Risk Factor of Life Satisfaction}

As hypothesized, acculturative stressors negatively predicted life satisfaction; however, the impact of different domains of acculturative stressors on life satisfaction varied between the Hong Kong and Australian samples. Specifically, academic work played a negative role in the prediction of life satisfaction in both samples. Social interaction made a significant negative contribution to predicting life satisfaction in the Hong Kong sample, whereas financial difficulty had a negative effect on predicting life satisfaction in the Australian sample. These findings indicate that social interaction and academic work are the major risk factors of life satisfaction for mainland Chinese students in Hong Kong, and academic work and financial difficulty are the major risk factors of life satisfaction for Chinese students in Australia. Unlike other groups of travelers and immigrants, international students go overseas to advance their education. Educational achievement and success are highly valued in Asian families. ${ }^{56}$ Chinese students in overseas universities want to make a good impression on their hosts and on behalf of their families by achieving academic success. ${ }^{57}$ These high expectations constitute a source of stress for Chinese students, ${ }^{58}$ which is associated with general satisfaction with the travel experience. ${ }^{30}$

We found the negative predictive effect of social interaction on life satisfaction in the Hong Kong sample only. This finding is consistent with a previous cross-cultural comparative study that found a link between interactions with host nationals and psychological distress in a group of Malaysian students in Singapore but not in Singaporean and Malaysian students in New Zealand. ${ }^{23}$ It is also consistent with a previous finding that the levels of social interaction with locals made no significant contribution to predicting the mental health of Chinese students attending school in Australia. ${ }^{21}$ As found in this study, the mainland Chinese students in Hong Kong interacted with Hong Kong nationals more than the Chinese students in Australia interacted with Australians. Instead, they likely interacted primarily with other Chinese students or Chinese immigrants. Thus, the students may have encountered more problems in interaction with local residents because of cultural and social differences. In a collective Chinese society, harmonious relationships with other people and in society are highly valued, which we found to reduce daily life stress. ${ }^{59}$ Future researchers should study the quality of social interaction in the host society. Another possible explanation is that the majority (45.6\%) of the mainland students in the Hong Kong sample had lived in Hong Kong for less than 1 year, whereas the majority (32.6\%) of the Australian sample had been in Australia for more than 3 years. The challenges of establishing a new social network in the host society is a major risk factor of poor mental health for Chinese immigrants in their first year in Hong Kong. ${ }^{60}$

In this study, a unique risk factor for the Australian sample was financial difficulty. Because research students in Hong Kong are fully sponsored by their universities, more than $60 \%$ of the mainland Chinese students in Hong Kong in the scale validation study reported no financial problems. Thus, we did not assess financial difficulty in the Hong Kong 
sample. However, most Chinese students in Australia were financially self-supported. Furthermore, the cost of studying and living is much higher in Australia than it is in Hong Kong. The difficulty of paying for overseas study constitutes a source of acculturative stress for Chinese students in Australia and has a negative impact on their life satisfaction.

We found no significant predictive effect of life satisfaction for language deficiency in either sample. We reached this conclusion on the basis of the significance test of the $\beta$-weight of language deficiency in the hierarchical regression model on life satisfaction (see Table 3 ). However, $\beta$-weight may underestimate the importance of a predictor that makes a strong joint contribution to explaining a dependent variable but does not make a strong unique contribution. ${ }^{61}$ As seen in the results of the hierarchical regression model, language deficiency made a significant joint contribution with other domains of acculturative stressors to predicting life satisfaction in both samples. Furthermore, the correlation of language deficiency and life satisfaction was significant in both samples (see Table 3), which is consistent with the previous finding that better English-language skills have a significant correlational relationship with life satisfaction. ${ }^{10}$ Thus, the role of English-language proficiency in predicting the life satisfaction of Chinese international students needs further investigation.

\section{Meaning of Life as a Protective Factor of Life Satisfaction in Acculturation}

We found that meaning of life is a protective factor in the level of life satisfaction of Chinese students in Australia and Hong Kong. Specifically, meaning of life partially mediated the relationship between acculturative stress and life satisfaction in both samples. This is consistent with the previous finding that meaning of life partially mediates the link between perceived stress and life satisfaction. ${ }^{44}$ Students who experience a lower level of acculturative stress are more likely to search for more personal meaning in their lives, which is consistent with the previous finding that perceived acculturative stress was a significant negative predictor of meaning in life. ${ }^{62}$ Therefore, finding more personal meaning in life is related to increased satisfaction with life in the host society. This indicates that acculturative stress has a direct negative effect on life satisfaction and an indirect effect on life satisfaction via meaning of life among Chinese students studying abroad. Lower levels of acculturative stress are associated with a higher level of meaning of life, which leads to a higher level of life satisfaction. We observed this effect in the Hong Kong and Australian samples. Two ways to increase the level of life satisfaction in Chinese international students are to decrease the various types of acculturative stressors that they encounter in the host society and to help them find meaning and purpose in their overseas lives from various sources.

\section{Theoretical and Practical Implications}

This study has theoretical and practical implications for acculturation and mental health research. First, although investigators have not widely used the resilience framework in studying the mental health of study-abroad students, we examined the protective function of meaning of life on level of life satisfaction, which is conceptually classified as a positive dimension of psychological well-being. Guided by the resilience framework, future researchers could examine other protective factors and use other positive indicators of psychological well-being, such as positive emotions and postmigration growth, to further investigate positive adaptation outcomes for study-abroad students. Second, we adopted a comparative approach to understand the contextual issues that shape the acculturative experiences of Chinese students in Australia and Hong Kong. This approach has yielded interesting similarities and differences and has contributed to our understanding of the contextual impact in acculturation research.

Our findings also have practical implications for college health services. Host universities must set up a multidisciplinary team to help Chinese international students adapt to their host societies. We also encourage them to find ways to facilitate the academic work of Chinese students by organizing supervisory panels and peer-learning groups at the departmental level. ${ }^{12}$ Cooperative learning and curricular change are other ways to meet the challenges of cross-cultural educational situations. ${ }^{11}$ English-language centers should not only provide English-enhancement programs, but also teach international students how to make presentations in English and how to engage in group discussions. For mainland Chinese students, the Hong Kong universities could broaden their social network by organizing various social activities to help them make more local and foreign friends. The student union or student associations could play an active role in initiating such activities. Student counseling centers could present intercultural training programs that provide a range of experiential opportunities to help international students understand cultural differences and appreciate similarities in a multicultural situation. ${ }^{11}$ For example, the Excellence in Cultural Experiential Learning and Leadership program, which Mak et al $^{63}$ developed in Australia, has helped international students foster sociocultural competencies through experiential social learning and cultural mapping approaches. Student affairs personnel at Hong Kong universities can steer mainland Chinese students toward "adopted" local families to establish continuous relationships with and gain social support from local residents in the course of their study. Last, international student offices (or related offices) in Australian universities could provide Chinese students with more financial support by, for example, offering more scholarships to deserving international students, providing low-interest loans, creating more on- and off-campus part-time job opportunities, and supplying accommodation at rents lower than the market price.

To strengthen the protective factor of meaning of life, counselors are encouraged to integrate meaning into the counseling process through meaning-centered counseling. ${ }^{64}$ Developing culturally sensitive intervention programs for Chinese students is of particular importance. Counselors can help these students find meaning in their relationships 
with others and with the host society. They can also assist Chinese students in understanding and affirming their reasons for migrating to such places as Australia and Hong Kong. This is particularly helpful for students who are undergoing stressful migration experiences and questioning their motives for studying overseas. Counselors should therefore ascertain the reasons that international students have chosen to study overseas and help them to find positive meaning in their decisions.

\section{Limitations}

This study has several limitations. First, because we obtained ethical approval only from the University of Melbourne, we recruited all Chinese participants in Australia only from this university. Thus, the generalization of the results from this sample to the total population of Chinese students attending school in Australia is limited. Second, as with all mediation analyses, alternative models may also be consistent with the data. ${ }^{52}$ Third, because we e-mailed the questionnaire via the Web mail system at the University of Hong Kong and sent it through the administrative staff at the International Student Office of the University of Melbourne, we do not know exactly how many students received the e-mail invitation. Thus, we were unable to estimate the response rate. Fourth, the differences between the 2 samples in age and in terms of their duration of residence in the host society may have influenced the differences in the results of the study. Last, because we used a cross-sectional rather than longitudinal research design, we cannot determine the causal relationships among the variables. Future researchers should use a longitudinal research design to ascertain the causality of the study variables.

\section{ACKNOWLEDGMENT}

This study was supported by a 2006 Endeavour Australia Cheung Kong Award.

The authors thank the Graduate School of the University of Hong Kong and the International Student Office of the University of Melbourne for their help with the data collection.

\section{NOTE}

For comments and further information, address correspondence to Dr Jia-Yan Pan, Department of Social Work and Social Administration, University of Hong Kong, Pok Fu Lam Road, Hong Kong (e-mail: jiayan2004@msn. com).

\section{REFERENCES}

1. Mak AS, Nesdale D. Migrant distress: the role of perceived racial discrimination and coping resources. J Appl Soc Psychol. 2001;31:2632-2647.

2. Dion KL, Dion KK. Chinese adaptation to foreign cultures. In Bond MH, ed. The Handbook of Chinese Psychology. Hong Kong: Oxford University Press; 1996:457-478.

3. Jou YH, Fukada H. Stress and social support in mental and physical health of Chinese students in Japan. Psychol Rep. 1997;81:1303-1312.

4. Joiner TE Jr, Walker RL. Construct validity of a measure of acculturative stress in African Americans. Psychol Assess. 2002; $14: 462-466$.

5. Xu J. Chinese students' adaptation to leaning in an American university: a multiple case study [PhD thesis]. Lincoln, NE: University of Nebraska; 2002.

6. Sheh S. Adjustment of Hong Kong students at the University of Alberta [doctoral thesis]. Alberta, Canada: University of Alberta; 1994.

7. Swagler MA, Ellis MV. Crossing the distance: adjustment of Taiwanese graduate students in the United States. J Couns Psychol. 2003;50:420-437.

8. Lu D. Facing dilemmas: Chinese students in the United States, 1979-1989 [doctoral thesis]. Eugene, OR: University of Oregon; 1998.

9. Mak AS, Barker MC. Social integration: strategies to foster migrants' effective participation in a group. Proceedings of the Second International Asian Health and Wellbeing Conference; Auckland, New Zealand; Nov. 11, 13-14, 2006.

10. Ward C, Masgoret AM. The experiences of international students in New Zealand: results of the national survey. Wellington, New Zealand: Ministry of Education; 2004.

11. Ho E, Holmes P, Cooper J; Migration Research Group, University of Waikato. Review and evaluation of international literature on managing cultural diversity in the classroom. Report for the New Zealand Ministry of Education. Wellington, New Zealand: Education New Zealand; 2004.

12. Ward C. International students: interpersonal, institutional and community impacts. Updates of the 2001 literature review. Wellington, New Zealand: Ministry of Education; 2006.

13. Williams FC, Butler SK. Concerns of newly arrived immigrant students: implications for school counselors. Prof School Couns. 2003;7:9-14.

14. Kim YY. Inquiry in intercultural and development communication. J Commun. 2005;55:554-577.

15. Ward C. Acculturation, social inclusion and psychological well-being of Asian migrants in New Zealand. Paper presented at: The Second International Asian Health and Wellbeing Conference; Auckland, New Zealand; Nov. 11, 13-14, 2006.

16. Lu L. Adaptation to British universities: homesickness and mental health of Chinese students. Counsel Psychol $Q$. 1990;3:225-232.

17. Lin L. Chinese graduate students' perception of their adjustment experiences at the University of Pittsburgh. Pittsburgh, PA: University of Pittsburgh; 1998.

18. Sun W, Chen GM. Dimensions of difficulties mainland Chinese students encounter in the United States. Paper presented at: The International Conference in Cross-Cultural Communication. Tempe, AZ; March 1997.

19. Berry JW. Psychology of acculturation: understanding individuals moving between cultures. In Brislin RW, ed. Applied Cross-Cultural Psychology. Newbury Park, CA: Sage; 1990:232254.

20. Hovey JD, King CA. Acculturative stress, depression, and suicidal ideation among immigrant and second-generation Latino adolescents. J Am Acad Child Adolesc Psychiatry. 1996;35:11831192.

21. Mak AS, Neil AL. How does social contact with locals impact on mental health: Chinese background international students in Australia. Prevention, protection and promotion. Proceedings of the Second International Asian Health and Wellbeing Conference; Auckland, New Zealand; Nov. 11, 13-14, 2006.

22. Mak AS, Tran C. Big five personality and cultural relocation factors in Vietnamese Australian students' intercultural social selfefficacy. Int J Intercult Relat. 2001;25:181-201.

23. Ward C, Kennedy A. Where's the "culture" in cross-cultural transition? Comparative studies of sojourner adjustment. J CrossCult Psychol. 1993;24:221-249.

24. Jasinskaja-lahtiI,LiebkindK, JaakkolaM, ReuterA.Perceived 
discrimination, social support networks, and psychological wellbeing among three immigrant groups. J Crosscultur Psychol. 2006;37:293-311.

25. Grotberg EH. Resilience for Today: Gaining Strength From Adversity. Westport, CN: Praeger; 2003.

26. Berry JW, Kim U, Minde T, Mok D. Comparative studies of acculturative stress. Int Migration Rev. 1987;21:491-511.

27. Gao MCF, Liu X. From student to citizen: a survey of students from the People's Republic of China (PRC) in Australia. Int Migration. 1998;36:27-48.

28. Rosenthal DA, Russell VJ, Thomson GD. A Growing Experience: The Health and Well-Being of International Students at the University of Melbourne. Melbourne, Australia: The University of Melbourne; 2006

29. Mang-So TF. Acculturation and psychological well-being among Chinese American college students. Dissertation Abstracts Int. 1995;56:499.

30. Laubscher LR. Toward a model of sojourner acculturation: acculturative stress among black South Africans studying in the United States. Dissertation Abstracts Int. 1996;57:102.

31. Neto F. Social adaptation difficulties of adolescents with immigrant backgrounds. Soc Behav Pers. 2002;30:335-345.

32. Minnard CV. A strong building: foundation of protective factors in schools. Children Schools. 2002;24:233-246.

33. Recker GT, Wong PT. Aging as an individual process: toward a theory of personal meaning. In Birren JE, Bengtson VL, eds. Emergent Theories of Aging. New York, NY: Springer; 1988:214-246.

34. DeVogler-Ebersole K, Ebersole P. Depth of meaning in life: explicit rating criteria. Psychol Rep. 1985;56:303-310.

35. Wong PT. Implicit theories of meaningful life and the development of the Personal Meaning Profile. In Wong PT, Fry PS, eds. The Human Quest for Meaning: A Handbook of Psychological Research and Clinical Application. Mahwah, NJ: Lawrence Erlbaum; 1998:111-140.

36. Baessler J, Oerter R. Aspects of meaning of life in different subcultures in Peru. Psychol Rep. 2003;92:1119-1130.

37. Prager E. Exploring personal meaning in an agedifferentiated Australian sample: another look at the Sources of Meaning Profile (SOMP). J Aging Stud. 1996;10:117-136.

38. Reker, GT. Sources of Personal Meaning Among MiddleAged and Older Adults: A Replication. Paper presented at the Annual Meeting of the Gerontological Society of America; November 18-22, 1988; San Francisco, CA.

39. Lin A. Exploring sources of life meaning among Chinese [master's thesis]. Langley, Canada: Trinity Western University; 2001.

40. Chamberlain K, Zika S. Religiosity, meaning in life, and psychological well-being. In Schumaker JF, ed. Religion and Mental Health. New York, NY: Oxford University Press; 1992:138-148.

41. Zika S, Chamberlain K. Relations of hassles and personality to subjective well-being. J Pers Soc Psychol. 1987;53:155-162.

42. Zika S, Chamberlain K. On the relation between meaning in life and psychological well-being. Br J Psychol. 1992;83:133145 .

43. Benejam G. Defining success factors for graduate students. Dissertation Abstracts Int Section B Sci Engineer. 2006;66:6261.

44. Wallace K, Lahti E. Spirituality as a mediator of the relation between perceived stress and life satisfaction. Gerontol. 2004;44:567.

45. Chiu E. Is migration necessarily bad for Asians' mental health? Prevention, protection and promotion. Proceedings of the
Second International Asian Health and Wellbeing Conference; Auckland, New Zealand; Nov. 11, 13-14, 2006.

46. Sandu DS, Asrabadi BR. Development of an acculturative stress scale for international students: preliminary findings. Psychol Rep. 1994;75:435-448.

47. Yang B, Clum GA. Measures of life stress and social support specific to an Asian student population. J Psychopathol Behav Assess. 1995;17:51-67.

48. Juarez AH. Development and validation of an instrument to measure stress in foreign students. Provo, UT: Brigham Young University; 1986

49. Shek DTL, Hong EW, Cheung, MYP. The Purpose in Life Questionnaire in a Chinese context. J Psychol. 121;1:77-83.

50. Diener E, Robert A, Emmons RJL, Griffin S. The Satisfaction with Life Scale. J Pers Assess. 1985;49:71-75.

51. Sachs J. Validation of the Satisfaction With Life Scale in a sample of Hong Kong university students. Psychologia. 2003;46:225-234.

52. Frazier PA, Tix AP, Barron KE. Testing moderator and mediator effects in counseling psychology. J Counsel Psychol. 2004;51:115-134.

53. Babiker IE, Cox JL, Miller PM. The measurement of cultural distance and its relationship to medical consultations, symptomatology and examination performance of overseas students at Edinburgh University. Soc Psychiatry. 1980;15:109-116.

54. Furnham A, Bochner S. Social difficulties in foreign culture: an empirical analysis of cultural shock. In: Bochner S, ed. Cultures in Contact: Studies in Cross-Cultural Interactions. Oxford, England: Pergamon;1982:161-198.

55. Galchenko I, Vijver FJR. The role of perceived cultural distance in the acculturation of exchange students in Russia. Int $J$ Intercult Relat. 2007;31:181-197.

56. Mordkowitz ER, Ginsburg HP. Early academic socialization of successful Asian American college students. Q NewsletterLab Compar Hum Cogn. 1987;9:85-91.

57. Graham MA. Acculturative stress among Polynesian, Asian and American students on the Brigham Young University-Hawaii campus. Int J Intercult Relat. 1983;7:79-103.

58. Ang RP, Huan VS. Academic Expectations Stress Inventory: development, factor analysis, reliability, and validity. EducPsychol Meas. 2006;66:522-539.

59. Triandis HC, Bontempo R, Villareal M J, Asai M, Lucca $\mathrm{N}$. Individualism and collectivism: cross-cultural perspectives on self-ingroup relationships. J Pers Soc Psychol. 1988;54:323-338.

60. Wong DFK. Differential impacts of stressful life events and social support on the mental health of mainland Chinese immigrant and local youth in Hong Kong: a resilience perspective. $\mathrm{Br} \mathrm{J}$ Soc Work. 2008;38:236-252.

61. Schroeder LD, Sjoquist DL, Stephan PE. Understanding Regression Analysis: An Introductory Guide. Thousand Oaks, CA: Sage; 1986.

62. Dunn MC. Psychological health and meaning in life: stress, social support, and religious coping in Latina and Latino immigrants [master's thesis]. College Park, MD: University of Maryland; 2007.

63. Mak AS, Westwood MJ, Barker MC, Ishiyama FI. Developing sociocultural competencies for success among international students: the EXCELL Programme. J Int Educ. 1998;9:33-38.

64. Wong PTP. Meaning-centered counseling. In Wong PTP, Fry PS, eds. The Human Quest for Meaning: A Handbook of Psychological Research and Clinical Applications. Mahwah, NJ: Lawrence Erlbaum; 1998:395-436. 


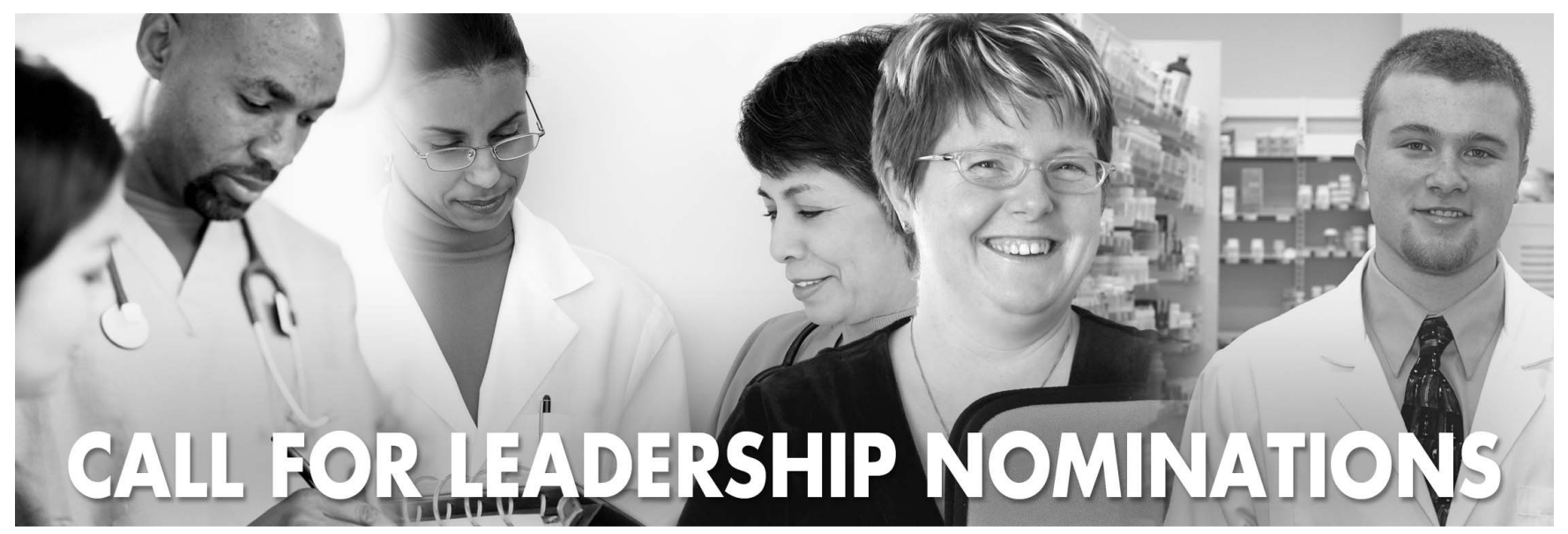

Among you are leaders with vision, dedicated colleagues, and college health experts. Let us know who these professionals are by nominating them for a position of leadership in your association.

Beginning September 4, 2008, ACHA will be accepting nominations for 2009-2010 for the offices of President-elect and Vice President.

Additionally, candidates for regional representatives to the Board of Directors will be presented on the national election ballot for election by regular and student individual members in their respective regions. Three of six regional representative positions will be up for election this year (Region II - Central, North Central, and Rocky Mountain College Health Associations; Region IV - Mid-Atlantic College Health Association; Region VI — Pacific Coast College Health Association).

Applicable leadership positions within the Administration, Advanced Practice Clinicians, Clinical Medicine, Health Promotion, Mental Health, Nurse-Directed Health Services, Nursing, and Pharmacy Sections will also be presented on the national election ballot for election by members within their section.

For details on how to submit a nomination, visit the ACHA website's "Members Only/Governance" area at www.acha.org or call (410) 859-1500, ext. 232. The deadline for officer and regional representatives nominations is November 14, 2008. The deadline for section nominations is December 10, 2008.

\section{$\checkmark$ American College Health Association}


Copyright of Journal of American College Health is the property of Heldref Publications and its content may not be copied or emailed to multiple sites or posted to a listserv without the copyright holder's express written permission. However, users may print, download, or email articles for individual use. 